\title{
Analysis of the influence of the spraying angle on the distribution of sprinkling intensity by a selected Turbo water nozzle
}

\author{
Piotr Piątek ${ }^{1}$ and Jerzy Gałaj ${ }^{2, *}$ \\ ${ }^{1}$ District Headquarters of the State Fire Service in Maków Mazowiecki, 6a Moniuszki St., 06-200 \\ Maków Mazowiecki, Poland \\ ${ }^{2}$ The Main School of Fire Service, Faculty of Fire Safety Engineering, 52/54 Slowackiego St., 01-629 \\ Warsaw, Poland
}

\begin{abstract}
The article describes the influence of the spraying angle on the distribution of the sprinkling intensity in the spray generated by the water nozzle Rosenbauer SELECT FLOW RB 101 EN. A partially modified laboratory stand normally used for testing of water nozzles was applied to carry out the experiments. Measurements of sprinkling intensity were made using the refined test method derived from the old Polish standard PN89/M-51028. This parameter was determined in a weight-volume manner using measuring containers. The paper presents only the results of tests carried out for a flow rate of $400 \mathrm{dm}^{3} / \mathrm{min}$ and three spraying angles: $30^{\circ}$, $60^{\circ}$ and $90^{\circ}$. The obtained results clearly indicate that the spraying angle is a very important parameter affecting the distribution of sprinkling intensity in spray jets generated by Turbo water nozzles. It has been observed that along with the change of the spraying angle, the values of many parameters adopted for analysis describing the distribution of the sprinkling intensity, such as the spraying surface and its dimensions (shape), the maximum length of the spray jet and the maximum sprinkling intensity, are changed. Finally, important conclusions were formulated both in the theoretical and practical aspects.
\end{abstract}

\section{Introduction}

Permanently for many years, water remains the most commonly used extinguishing agent [1]. Despite a number of advantages that justify its wide use, it has its drawbacks and limitations. The optimization of the water extinguishing process is still an unresolved problem. This should be understood as carrying out extinguishing actions in such a way as to fight a fire in the shortest possible time, while consuming the minimum necessary amount of water and causing the least possible fire damage. Therefore, the method of feeding water into the fire environment is very important. During rescue and firefighting operations, it is necessary to aim for a proper forming of the water jet. As early as in the middle of the 20th century, it was noticed that sprayed streams had much better fire

\footnotetext{
* Corresponding author: jgalaj@sgsp.edu.pl
} 
properties [2-5]. In contrast to solid jet, they are characterized by a much higher degree of water use and a more effective influence on flames. The extinguishing effect obtained in the case of their use is therefore much better [6].

The process of water spraying is easiest to define as the breakdown of water into drops caused by the impact of various forces, especially surface, gravity and aerodynamics [7]. A necessary condition for its initiation is to provide mechanical energy in an appropriate way [8]. Very often, the energy of the liquid itself is used for this purpose. Nowadays, in the extinguishing activities, for generating sprays, the most commonly used are Turbo water nozzles. Its universality speaks for it. They make it possible to shape water jets of different structure and parameters. In terms of construction and design, it belongs to the jet-whirl sprayers. Currently, there are also special nozzles available in the market such as the modern mist nozzle generating fog jets.

Despite the considerable diversity of water streams, researchers have managed to extract and classify the parameters used to describe them and compare them with each other. They were divided into external, characterizing its macrostructure and internal, related to its microstructure. The first ones include: mass or volume stream, spraying angle, range and distribution of liquid in the droplet stream. To the second, the average droplet diameters and the droplets spectrum can be included [7]. In fire-fighting technology, the distribution of liquid in a stream is usually determined by means of an indicator called the sprinkling intensity. This parameter is defined as the volume of water falling on a unit of surface in a given time. It is one of the key indicators used in assessing the firefighting effectiveness of water jets and is determined experimentally. Many years of experiments proved that there is a strong correlation between the degree of water spraying and the obtained extinguishing efficiency $[3,6,9]$. Therefore, the study on the construction of Turbo water nozzles and the parameters of their streams [1, 6, 10-14] are constantly being carried out at research and development centers. Researchers are still looking for technical solutions to deliver water jets that provide the best possible firefighting performance under specific conditions. However, publications presenting the results of open-space experiments in real conditions are still missing. As a rule, literature items refer to spraying devices, such as sprinklers, fog heads, etc., used mainly in technical building protection systems [3, 8, 15-16].

The purpose of this article is to determine the influence of the spraying angle on the distribution of the sprinkling intensity in the spray stream generated by the Rosenbauer RB $101 \mathrm{EN}$ water nozzle at a constant flow rate of $Q=400 \mathrm{dm}^{3} / \mathrm{min}$.

\section{Methodology and research procedure}

The experiment to investigate the influence of the spraying angle on the distribution of sprinkling intensity in the spray stream generated by the selected Turbo nozzle was carried out in August and September 2017 on the square located in front of the Laboratory of the Fire and Rescue Equipment Department of the Main School of Fire Service. A slightly modified station located in the laboratory was used for the measurements. The tested nozzle (15) was mounted permanently in a metal tripod (16) at an angle of $15^{\circ}$ to the ground. Droplets forming a spray of water jet fell on a grid of evenly spaced measuring containers (17) with the dimensions of the inlet opening $325 \mathrm{~mm} \times 225 \mathrm{~mm}$. The spray angle was measured using the GAM 270 MFL Professional electronic protractor. The mass of water collected in containers was determined using the RADWAG WLC $60 / \mathrm{C} 2 / \mathrm{K}$ precision scales (4). The nozzle was powered by a set of electric pumps connected in series (9). All devices recording measurement parameters such as atmospheric pressure, ambient temperature, wind direction and speed, water flow rate and nozzle supply pressure have been connected to the measuring cabinet (1). Hence, the recorded data was sent to a PC (3). Thanks to the specially designed InTouch WindowViewer 2014 R2 SP1 software it was 
possible to constantly monitor the mentioned parameters on the monitor screen (2), and then save the results and export them to .xlsx format, which can be read using MS Excel.

The scheme of the measurement station is shown in Figure 1.

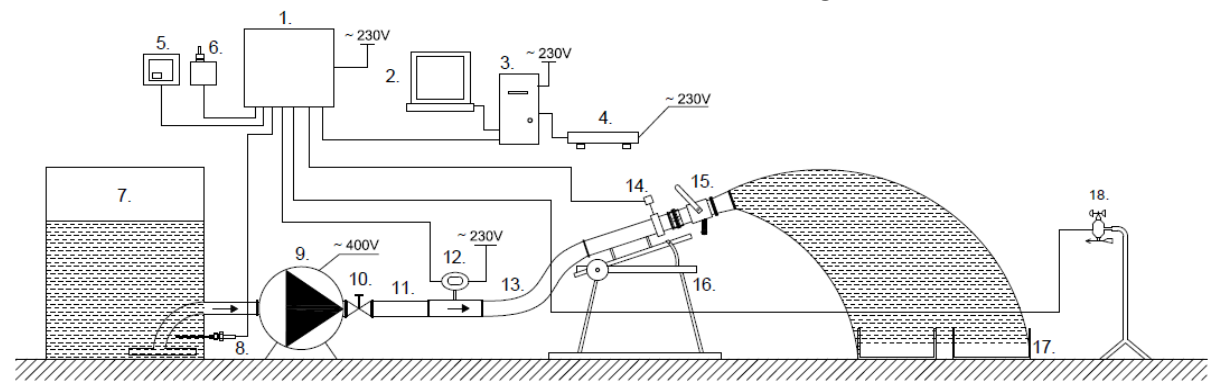

Fig. 1. The scheme of the measurement station (1 - measuring cabinet; 2 - monitor, 3 - computer PC; 4 - precision scales; 5 - temperature converter; 6 - ambient pressure converter; 7 - two water tanks with a total usable capacity $>1,5 \mathrm{~m}^{3} ; 8$ - temperature sensor $\mathrm{Pt} 100 \Omega / 0^{\circ} \mathrm{C} ; 9$ - set of power electric pumps connected in series; 10 - shut-off valve; 11,13 - shortened sections of the W-52 fire hose; 12 electromagnetic flowmeter; 14 - pressure converter; 15 - Turbo water nozzle; 16 - metal stand with the function of adjusting the angle of inclination, 17 - measuring containers; 18 - electronic anemometer).

A PWT 52/1,3-2,3-3-4 water nozzle type SELECT FLOW RB 101 EN from Rosenbauer International AG was used as a subject of study. It is a new generation device found in many rescue and firefighting units. The nozzle has a mobile, rotating racks turbine made of metal. The adjustment ring of the flow allows for a change in the water flow rate of $130 / 230 / 300 / 400 \mathrm{dm}^{3} / \mathrm{min}$. In turn, the coated, impact-resistant pivoting head of the nozzle allows a smooth change in spraying angle to $100^{\circ}$ [17].

The view of the nozzle is presented in Figure 2.

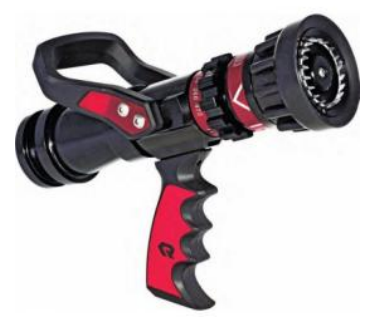

Fig. 2. The subject of study - Turbo water nozzle Rosenbauer RB 101 EN [17].

Figures 3 and 4 show the schematic diagram of the containers grid and the measurement of the spraying angle during one of the experiments.

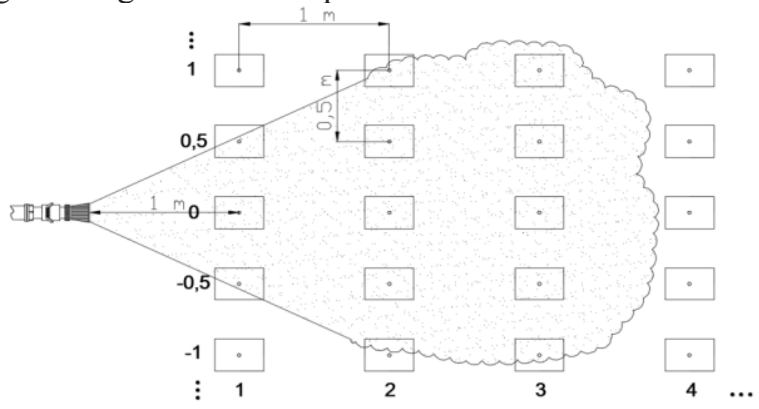

Fig. 3. Schematic diagram of the containers grid [13] 


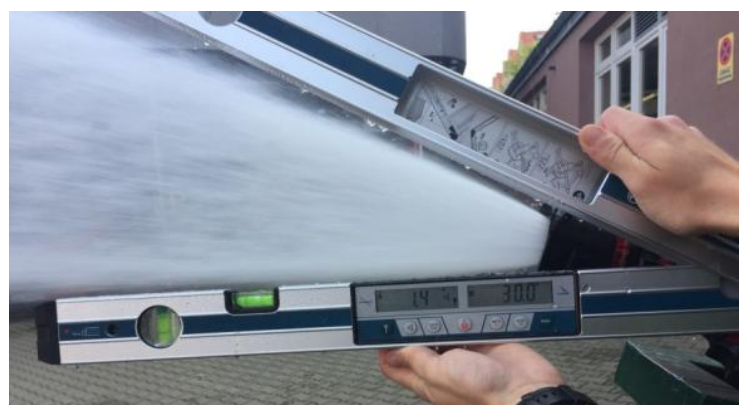

Fig. 4. A measurement of spraying angle during the experiment [13]

During the tests carried out for each measurement, the following parameters were determined:

1. $t_{p}$ - duration of the measurement, min;

2. $t_{o}$ - ambient temperature (average value), ${ }^{\circ} \mathrm{C}$;

3. $p_{\text {atm }}-$ atmospheric pressure (mean value), $\mathrm{hPa}$;

4. $p_{p r}$ - pressure at the inlet to the nozzle (average value), bar;

5. $Q$-- water flow rate (average value), $\mathrm{dm}^{3} / \mathrm{min}$;

6. $t_{w}$ - water temperature during the test (mean value), ${ }^{\circ} \mathrm{C}$;

7. $v_{w}-$ wind speed (average value), $\mathrm{m} / \mathrm{s}$.

The computer application also recorded the direction of the wind. However, the numerical value would not reflect the real impact of this factor and therefore the impact of air movement on the results was characterized in a descriptive manner. The applied test method can be defined as weight-volume with the use of measuring containers. It was modeled on a check of the average and maximum length and width of the spray stream from the currently obsolete Polish standard [18]. It provided for the possibility of carrying out measurements in an open space. Due to the time-consuming nature of the research and relatively unfavorable weather conditions, some deviations from the recommendations indicated in the standard [18] have been maintained. Finally, the tests were carried out on days without precipitation at a maximum wind speed of $2 \mathrm{~m} / \mathrm{s}$. The measurement procedure has been discussed and described in detail in [13].

The sprinkling intensity was estimated indirectly by mass measurement. The measured mass of water collected in the measuring container at a given time was converted into a volume, taking into account the density of the liquid at a given temperature. According to [18], the measurement time should not be shorter than 2 minutes. In fact, each one-off study was carried out as long as possible. The maximum number of measuring containers used was 210 . The sprinkling intensity $I_{z}$ was calculated according to the formula (1):

$$
I_{\mathrm{z}}=V /\left(A \cdot t_{\mathrm{p}}\right)=m_{\mathrm{w}} /\left(\rho_{\mathrm{w}} \cdot A \cdot t_{\mathrm{p}}\right)
$$

where:

$V-$ volume of water caught in the measuring container, $\mathrm{mm}^{3}$;

$A$ - surface of the inlet of the measuring container, $\mathrm{mm}^{2}\left(\mathrm{~A}=73125 \mathrm{~mm}^{2}\right)$;

$m_{\mathrm{w}}-$ mass of water caught in the measuring container, $\mathrm{g}$;

$\rho_{\mathrm{w}}-$ density of water caught in the measuring container, $\mathrm{g} / \mathrm{mm}^{3}$.

\section{Test results}

The values of the parameters monitored during every single test of the Turbo water nozzle Rosenbauer RB $101 \mathrm{EN}$ obtained for a flow rate of $400 \mathrm{dm}^{3} / \mathrm{min}$ and three spraying angles 
of $30^{\circ}, 60^{\circ}$ and $90^{\circ}$ were collected in Tables 1-3. Values of standard deviations $\sigma$ were also calculated and given in the same tables.

Table 1. Values and standard deviations of parameters measured during the experiment with Rosenbauer RB $101 \mathrm{EN}$ at spraying angle $\varphi=30^{\circ}$ and flow rate $Q=400 \mathrm{dm}^{3} / \mathrm{min}$ [13].

\begin{tabular}{|c|c|c|c|c|c|c|c|}
\hline \multirow{2}{*}{$\begin{array}{c}\text { Average } \\
\text { value }\end{array}$} & $\begin{array}{c}\boldsymbol{t}_{\mathbf{p}} \\
{[\mathbf{m i n}]}\end{array}$ & $\begin{array}{c}\boldsymbol{t}_{\mathbf{0}} \\
{\left[{ }^{\circ} \mathbf{C}\right]}\end{array}$ & $\begin{array}{c}\boldsymbol{p}_{\text {atm }} \\
{[\mathbf{h P a}]}\end{array}$ & $\begin{array}{c}\boldsymbol{p}_{\mathbf{p r}} \\
{[\mathbf{b a r}]}\end{array}$ & $\begin{array}{c}\boldsymbol{Q} \\
{\left[\mathbf{d m}^{3} / \mathbf{m i n}\right]}\end{array}$ & $\begin{array}{c}\boldsymbol{t}_{\mathbf{w}} \\
{\left[{ }^{\circ} \mathbf{C}\right]}\end{array}$ & $\begin{array}{c}\boldsymbol{v}_{\mathbf{w}} \\
{[\mathbf{m} / \mathbf{s}]}\end{array}$ \\
\hline \multirow{2}{*}{$\boldsymbol{\sigma}$} & 4,25 & 20,9 & 1023 & 5,12 & 399,7 & 16,5 & 1,47 \\
\hline & nd. & 0,0 & 0 & 0,05 & 1,5 & 0,0 & 0,51 \\
\hline
\end{tabular}

Table 2. Values and standard deviations of parameters measured during the experiment with Rosenbauer RB $101 \mathrm{EN}$ at spraying angle $\varphi=60^{\circ}$ and flow rate $Q=400 \mathrm{dm}^{3} / \mathrm{min}$ [13].

\begin{tabular}{|c|c|c|c|c|c|c|c|}
\hline $\begin{array}{c}\text { Average } \\
\text { value }\end{array}$ & $\begin{array}{c}\boldsymbol{t}_{\mathbf{p}} \\
{[\mathbf{m i n}]}\end{array}$ & $\begin{array}{c}\boldsymbol{t}_{\mathbf{0}} \\
{\left[{ }^{\circ} \mathbf{C}\right]}\end{array}$ & $\begin{array}{c}\boldsymbol{p}_{\text {atm }} \\
{[\mathbf{h P a}]}\end{array}$ & $\begin{array}{c}\boldsymbol{p}_{\mathbf{p r}} \\
{[\mathbf{b a r}]}\end{array}$ & $\begin{array}{c}\boldsymbol{Q} \\
{\left[\mathbf{d m}^{3 / \mathbf{m i n}]}\right.}\end{array}$ & $\begin{array}{c}\boldsymbol{t}_{\mathbf{w}} \\
{\left[{ }^{\circ} \mathbf{C}\right]}\end{array}$ & $\begin{array}{c}\boldsymbol{v}_{\mathbf{w}} \\
{[\mathbf{m} / \mathbf{s}]}\end{array}$ \\
\hline $\boldsymbol{\sigma}$ & 2,50 & 20,7 & 1002 & 5,21 & 401,8 & 20,0 & 0,73 \\
\hline & nd. & 0,0 & 0 & 0,03 & 1,1 & 0,0 & 0,34 \\
\hline
\end{tabular}

Table 3. Values and standard deviations of parameters measured during the experiment with Rosenbauer RB $101 \mathrm{EN}$ at spraying angle $\varphi=90^{\circ}$ and flow rate $Q=400 \mathrm{dm}^{3} / \mathrm{min}$ [13].

\begin{tabular}{|c|c|c|c|c|c|c|c|}
\hline \multirow{2}{*}{$\begin{array}{c}\text { Average } \\
\text { value }\end{array}$} & $\begin{array}{c}\boldsymbol{t}_{\mathbf{p}} \\
{[\mathbf{m i n}]}\end{array}$ & $\begin{array}{c}\boldsymbol{t}_{\mathbf{0}} \\
{\left[{ }^{\circ} \mathbf{C}\right]}\end{array}$ & $\begin{array}{c}\boldsymbol{p}_{\text {atm }} \\
{[\mathbf{h P a}]}\end{array}$ & $\begin{array}{c}\boldsymbol{p}_{\mathbf{p r}} \\
{[\mathbf{b a r}]}\end{array}$ & $\begin{array}{c}\boldsymbol{Q} \\
{\left[\mathbf{d m}^{3} / \mathbf{m i n}\right]}\end{array}$ & $\begin{array}{c}\boldsymbol{t}_{\mathbf{w}} \\
{\left[{ }^{\circ} \mathbf{C}\right]}\end{array}$ & $\begin{array}{c}\boldsymbol{v}_{\mathbf{w}} \\
{[\mathbf{m} / \mathbf{s}]}\end{array}$ \\
\cline { 2 - 8 } & 2,50 & 20,8 & 1002 & 5,26 & 404,9 & 19,9 & 1,40 \\
\hline $\boldsymbol{\sigma}$ & nd. & 0,0 & 0 & 0,03 & 0,9 & 0,0 & 0,38 \\
\hline
\end{tabular}

Graphs illustrating the three-dimensional distribution of sprinkling intensity, made in the SURFER 15 program are presented in Figure 5. The classic coordinate system X, Y, Z has been changed into the $\mathrm{S}, \mathrm{L}$, and $\mathrm{I}_{\mathrm{z}}$ system, where:

$\mathrm{S}$ - distances between containers in a direction perpendicular to the axis of the nozzle, $\mathrm{m}$; $\mathrm{L}$ - distances between containers in a direction parallel to the axis of the nozzle, $\mathrm{m}$; $\mathrm{I}_{\mathrm{z}}$ - sprinkling intensity in a given measuring point (the center of measuring container), $\mathrm{mm} / \mathrm{min}$
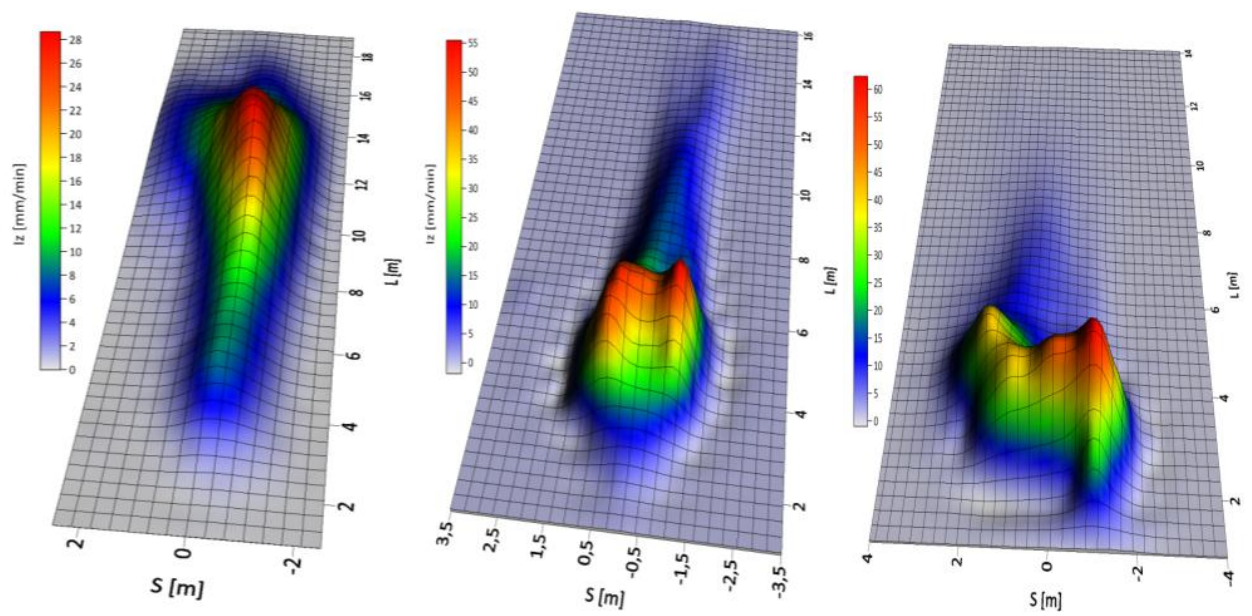

Fig. 5. Distribution of sprinkling intensity $I_{z}$ in a three-dimensional system for the spray stream generated by the Rosenbauer RB 101 ENG nozzle at a flow rate of $Q=400 \mathrm{dm}^{3} / \mathrm{min}$ and spraying angles $\varphi=30^{\circ}$ (on the left), $\varphi=60^{\circ}$ (in the center) and $\varphi=90^{\circ}$ (on the right) [13].

Figures 6-7 presents sample charts, also made in the SURFER 15 application, showing in succession: two-dimensional distribution of sprinkling intensity in the form of a layer 
projection on the horizontal plane and the sprinkling intensity along the central (longitudinal) axis of the stream for the test performed at the spraying angle $\varphi=60^{\circ}$ and flow rate $Q=400 \mathrm{dm}^{3} / \mathrm{min}$.

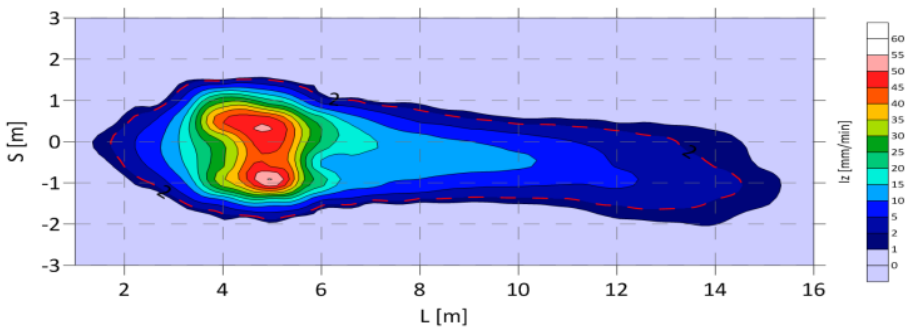

Fig. 6. Layer projection of the sprinkling intensity distribution $I_{\mathrm{Z}}$ on the horizontal plane for the spray stream generated by the Rosenbauer RB $101 \mathrm{EN}$ nozzle at the spraying angle $\varphi=60^{\circ}$ and the flow rate $Q=400 \mathrm{dm}^{3} / \min [13]$.

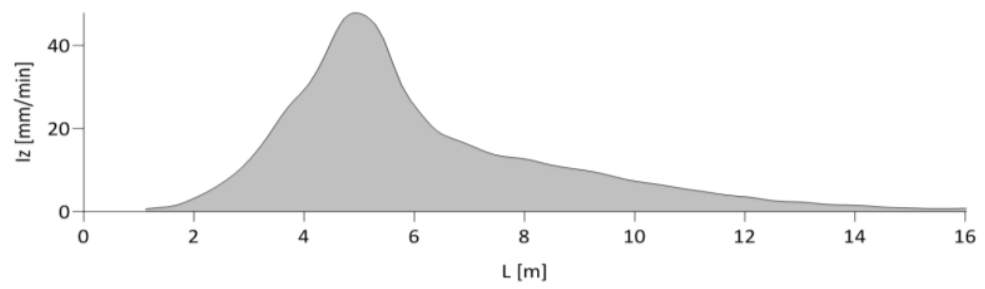

Fig. 7. Sprinkling intensity $I_{\mathrm{z}}$ along its central axis for the spray stream generated by the Rosenbauer RB 101 EN nozzle at the spraying angle $\varphi=60^{\circ}$ and the flow rate $Q=400 \mathrm{dm}^{3} / \mathrm{min}$ [13].

\section{Analysis of the results}

Due to the nature of the publication, the analysis of the results was based on the following four key criteria:

1) the spraying surface $A_{z}$ understood as the area in which $I_{z} \geq 2 \mathrm{~mm} / \mathrm{min}$; 2) the maximum sprinkling intensity $I_{z \max }$ defined as the global maximum value $I_{z}$ within the designated area of $\mathrm{A}_{\mathrm{z}}$;

3) maximum length (range) of the spray $L_{\max }$, which should be understood as the distance measured in a straight line along the longitudinal axis of the nozzle from its outlet nozzle to the farthest-away point at which $I_{z} \geq 2 \mathrm{~mm} / \mathrm{min}$;

4) the number of $L_{\mathrm{el}}$ local extrema i.e. points with the highest local value of $I_{\mathrm{z}}$.

The values of the above mentioned parameters for the spray generated by the Rosenbauer RB $101 \mathrm{EN}$ nozzle at a flow rate of $Q=400 \mathrm{dm}^{3} / \mathrm{min}$ and three tested spraying angles $\varphi=30^{\circ}, 60^{\circ}$ and $90^{\circ}$ were collected in Table 4 .

Table 4. Values of parameters adopted for the analysis of the spray stream generated by the Rosenbauer RB $101 \mathrm{EN}$ nozzle at a flow rate of $Q=400 \mathrm{dm}^{3} / \mathrm{min}$ and spraying angles $\varphi=30^{\circ}, 60^{\circ}$ and $90^{\circ}$.

\begin{tabular}{|c|c|c|c|c|c|}
\hline $\begin{array}{c}\boldsymbol{\varphi} \\
{\left[{ }^{\circ}\right]}\end{array}$ & $\begin{array}{c}\boldsymbol{p}_{\mathbf{p r}} \\
{[\mathbf{b a r}]}\end{array}$ & $\begin{array}{c}\boldsymbol{A}_{\mathbf{z}} \\
{\left[\mathbf{m}^{\mathbf{2}}\right]}\end{array}$ & $\begin{array}{c}\boldsymbol{I}_{\mathbf{z} \text { max }} \\
{[\mathbf{m m} / \mathbf{m i n}]}\end{array}$ & $\begin{array}{c}\boldsymbol{L}_{\max } \\
{[\mathbf{m}]}\end{array}$ & $\begin{array}{c}\boldsymbol{L}_{\text {el }} \\
{[-]}\end{array}$ \\
\hline 30 & 5.12 & 42.78 & 28.69 & 17.36 & 1 \\
\hline 60 & 5.21 & 26.96 & 55.47 & 14.55 & 2 \\
\hline 90 & 5.26 & 28.55 & 62.33 & 9.80 & 2 \\
\hline
\end{tabular}

Data collected in Table 4 are supplemented with their graphic interpretation. Figure 8 shows the parameters $A_{\mathrm{z}}$ and $L_{\max }$ as a function of the spraying angle $\varphi$. The graph in Figure 
9 shows the changes in the $I_{\mathrm{z} \max }$ as a function of the spraying angle $\varphi$. Taken on the prepared characteristics $A_{\mathrm{z}}=\mathrm{f}(\varphi), I_{\mathrm{z} \text { max }}=\mathrm{f}(\varphi)$ and $L_{\max }=\mathrm{f}(\varphi)$ the trend lines are an attempt to approximate the observed tendencies with polynomial functions.

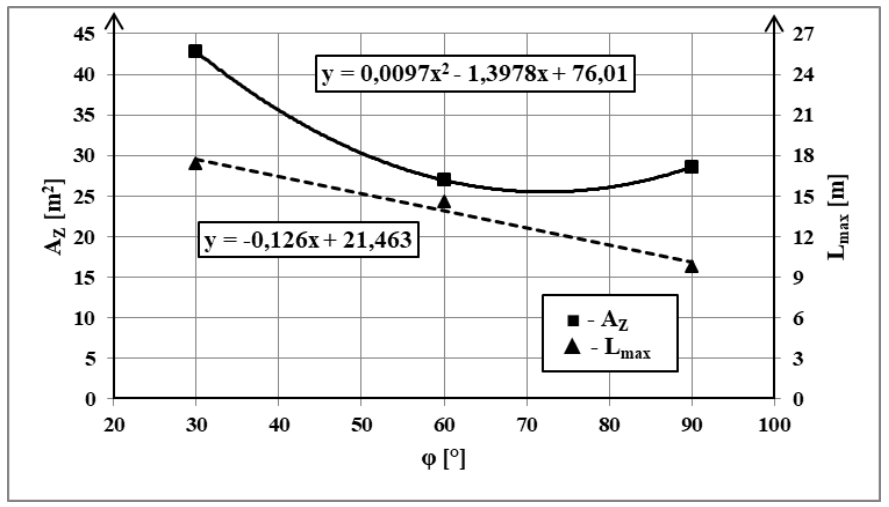

Fig. 8. The values of the sprinkling area $A_{\mathrm{z}}$ and the maximum length of the spray stream $L_{\max }$ for the three tested spraying angles $\varphi$ and the flow rate $Q=400 \mathrm{dm}^{3} / \mathrm{min}$.

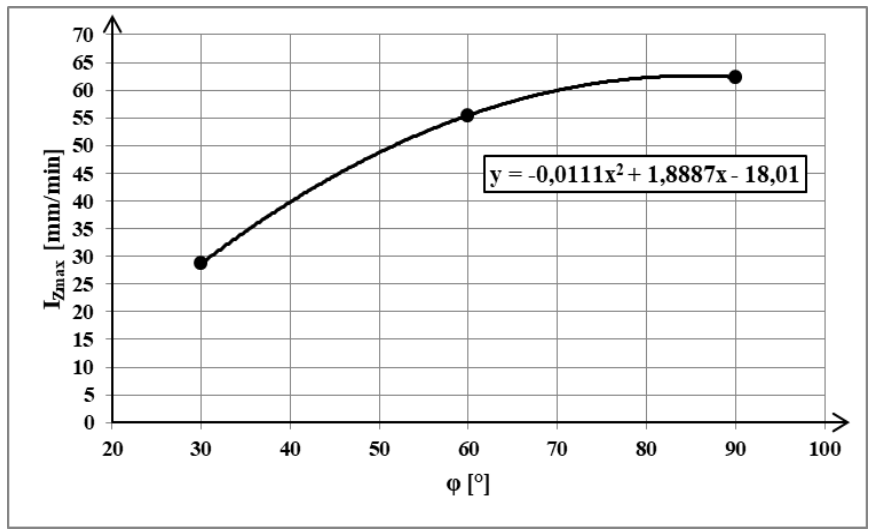

Fig. 9. Values of maximum sprinkling intensity for the three tested spraying angles $\varphi$ and the flow rate $Q=400 \mathrm{dm}^{3} / \mathrm{min}$

\section{Summary and conclusions}

Results of the tests determining the influence of the spraying angle on the distribution of the sprinkling intensity in the spray stream generated by the Rosenbauer RB 101 EN water nozzle at a flow rate of $\mathrm{Q}=400 \mathrm{dm}^{3} / \mathrm{min}$ are presented and discussed in the paper. The following general conclusions have been formulated on the basis of the experiments carried out:

1. The largest values of the spraying surface $A_{\mathrm{z}}$ are obtained for small spraying angles. In addition, after exceeding a certain value of the angle $\varphi$, these changes are so small that it can be assumed that the spraying surface, as regards the size, does not change.

2. The largest ranges of the throw of the spray stream $L_{\max }$ are obtained, similarly to the parameter $A_{\mathrm{z}}$, at the smallest spraying angles. This is mainly due to the greatest kinetic energy of these streams. $L_{\max }$ decreases linearly with growing of the spraying angle according to the equation $L_{\max }(\varphi)=-0.126 \varphi+21.463$. The determination coefficient of the selected approximation function is very high and amounts to $\mathrm{R}^{2}=0.9785$. 
3. As the spraying angle increases, the values of the maximum sprinkling intensity $I_{\mathrm{z} \max }$ also increases. The highest value of the maximum sprinkling intensity of $62.33 \mathrm{~mm} / \mathrm{min}$ was obtained with the spraying angle $\varphi=90^{\circ}$.

4. For the spray streams with angles $\varphi=60^{\circ}$ and $\varphi=90^{\circ}$, two local extrema of $\mathrm{I}_{z}$ are observed on the spraying surface, while for the spray angle $\varphi=30^{\circ}$ only one local extremum was observed, which is at the same time the global extreme.

5. The change of the spray angle causes changes of the shape of sprinkling surface from the elliptic sprinkling surface with the elongated longitudinal axis for the spraying angle $\varphi=$ $30^{\circ}$ through almost circular shape for angle $\varphi=60^{\circ}$, up to elliptical shape with an elongated transverse axis for $\varphi=90^{\circ}$.

Due to the few publications on the spraying of water streams in the open space, the authors recognize the need for further research in this area. These works should include within their scope the feeding of water jets from nozzles with different construction solutions at different spraying angles and describe the influence of these factors on the parameters of the spraying surface, and thus on extinguishing efficiency.

\section{References}

1. Sz. Kokot-Góra, Techniques of operating with extinguishing jets (Air Press, Opole, 2015)

2. G. Grant, J. Brenton, D. Drysdale, Prog. Energy Combust. Sci. 26, 79 (2000)

3. J.R. Mawhinney, J.K. Richardson, Fire Technol. 33, 54 (1996)

4. M.M. Braidech, J.A. Neale, A.F. Matson, R.E. Dufour, The Mechanism of Extinguishment of Fire by Finely Divided Water (UL, New York, 1955)

5. D.J. Rasbash, Z.W. Rogowski, G.W.V. Stark, Combust. Flame 4, 223 (1960)

6. P.T. Grimwood, Flashover \& Nozzle Techniques (CEMAC, Destelbergen, 2002)

7. Z. Orzechowski, J. Prywer, Production and application of the spray liquid (WNT, Warsaw, 2008)

8. J. Roguski, P. Zbrożek, D. Czerwienko, Selected aspects of the use of water mist extinguishing equipment in construction facilities (CNBOP-PIB, Józefów, 2012)

9. P.T. Grimwood, Fog attack. Firefighting Strategy \& Tactics - An International View (FMJ Int., Burgess Hill, 1992)

10. J. Gałaj, T. Drzymała, D. Tabaka, Fire Safety and Technique 43, 51 (2016)

11. P. Piątek, Analysis of the influence of the inclination angle of the nozzle on the distribution of droplet diameters in the spray generated by the Turbo Master 52 nozzle (Bachelor's diploma thesis, SGSP, Warsaw, 2016)

12. J. Gałaj, T. Drzymała, P. Piątek, Procedia Engine. 172, 300 (2017)

13. P. Piątek, Comparative analysis of the influence of the spraying angle on the distribution of the spraying intensity in the spray produced by selected nozzles (Master's diploma thesis, SGSP, Warsaw, 2018)

14. T. Drzymała, J. Gałaj, Ł. Gorzkiewicz, Sci. J. SGSP 65(2), 119 (2018)

15. J. Gałaj, T. Drzymała, Sci. J. SGSP 34, 43 (2006)

16. J. Gałaj, S. Kieliszek, T. Drzymała, Sci. J. SGSP 35, 5 (2007)

17. http://sklep.mat-poz.pl/sprzet-i-umundurowanie-dla-strazy/2391-pradownicarosenbauer-rb-101.html, 20.08.2018

18. PN-89/M-51028 Fire equipment. Water nozzles for fire pumps 